\title{
PENENTUAN KAPASITAS PRODUKSI DENGAN METODE SIMPLEKS PADA UKM DI KOTA BATAM
}

\author{
Welly Sugianto \\ ${ }^{1}$ Fakultas Teknik dan Komputer, Universitas Putera Batam \\ email: welly@puterabatam.ac.id
}

\begin{abstract}
Abstrak: Penelitian ini dilakukan pada sebuah UKM yang membuat produk tahu, tempe dan susu kedelai. Penelitian ini mencoba memberikan solusi untuk menentukan komposisi jumlah produk yang mampu memaksimumkan laba. Metode yang digunakan adalah program linier dengan metode simpleks. Program linier dengan metode simpleks merupakan metode persamaan linier dengan model fungsi tujuan dan fungsi konstrain atau fungsi kendala. Tujuan pada penelitian ini adalah maksimalkan laba berdasarkan keuntungan yang diperoleh tiap produk dan berdasarkan fungsi kendala. Fungsi kendala disusun berdasarkan batasan yang ada pada UKM tersebut. Batasan tersebut yakni biaya bahan baku, biaya tenaga kerja, jam tenaga kerja dan kapasitas mesin. Metode simpleks digunakan untuk menentukan jumlah kapasitas produksi yang dapat memaksimumkan laba. Setelah itu dilakukan analisis sensitivitas untuk mengetahui rentang jumlah sumber daya agar keuntungan tetap tercapai.. Komposisi produk yang harus dibuat oleh UKM tersebut adalah tahu sebanyak 28,75 atau 29 kotak dan susu kedelai sebanyak 5 kotak. Hasil analisis sensitivitas menyatakan bahwa rentang nilai bahan baku adalah $420<$ b1 $<680$ dan rentang jumlah tenaga kerja adalah $0<$ b2 $<10.8333$. Jika nilai $b$ berada pada rentang tersebut maka profit akan tetap bernilai positif.
\end{abstract}

Kata kunci: Simpleks, UKM, Analisis Sesitivitas

Abstract: This research was conducted at a SME that makes tofu, tempeh and soy milk products. This study tries to provide a solution to determine the composition of the number of products that are able to maximize profits. The method used is a linear program with the simplex method. A linear program with the simplex method is a method of linear equations with objective function models and constraint functions. The purpose of this study is to maximize profits based on the benefits of each product and based on the constraint function. The constraint function is arranged based on the existing limitations on the UKM. These limits are the cost of raw materials, labor costs, labor hours and machine capacity. The simplex method is used to determine the amount of production capacity that can maximize profits. After that, a sensitivity analysis is carried out to determine the range of the number of resources so that the profit is still achieved. The results of the sensitivity analysis state that the range of raw material values is $420<b 1<680$ and the range of the number of workers is $0<b 2$ $<10.8333$. If the value of $b$ is in this range then the profit will still be positive.

Keywords: Simplex, SME, Sensitivity Analysis

\section{PENDAHULUAN}

Penelitian ini dilaksanakan pada sebuah UKM di kota Batam yang memproduksi tahu, tempe dan air tahu. UKM tersebut berdiri sejak 2010 dengan pangsa pasar sekitar $2 \%$ di kota batam. Persaingan yang ketat mendorong UKM tersebut untuk meningkatkan kinerjanya dalam segala aspek seperti kualitas, inovasi, efektivitas dan efisiensi.

Sampai saat ini UKM tersebut masih belum dapat menentukan kapasitas produksinya secara akurat. Kapasitas produksi ditentukan berdasarkan intuisi dan tidak ditentukan secara akurat berdasarkan pada sumber daya yang dimiliki. Dampak dari hal tersebut adalah laba yang diperoleh tidak optimal. Produk yang dibuat antara lain adalah tahu, tempe dan air tahu. Jumlah produk yang dibuat saat ini hanya berdasarkan pada intuisi dan tidak dihitung secara matang sehingga menimbulkan permasalahan penggunaan sumber daya yang tidak optimal yang mengakibatkan kelebihan bahan baku, 
produktivitas karyawan yang rendah serta tingkat penggunaan mesin yang rendah.

\section{TINJAUAN PUSTAKA}

Pendekatan secara umum untuk menyelesaikan permasalahan program linier dengan metode simpleks dengan cara mengkonversi permasalahan menjadi bentuk standar dengan beberapa karakteristik sebagai berikut (Balogun et al., 2012): (1) Seluruh konstrain dinyatakan dalam bentuk persamaan dengan menambahkan variabel slack atau variabel surplus; (2) Sisi kanan dari konstrain harus positif dan jika negatif maka kedua ruas atau kedua sisi konstrain harus dikalikan dengan -1; (3) Fungsi objektif harus berbentuk maksimalisasi. Untuk $\mathrm{n}$ variabel keputusan dan $\mathrm{m}$ konstrain, fungsi tujuan dan fungsi kendala atau konstrain ditunjukkan oleh persamaan 1 dan persamaan 2 (Nadar, 2016).

$$
\begin{aligned}
& \operatorname{Max} Z=\sum_{j=1}^{m} c_{j} x_{j}+\sum_{j=1}^{m} 0 s_{j} \\
& \sum_{j=1}^{m} a_{i j} x_{j}+s_{i}=b_{i}
\end{aligned}
$$

$\mathrm{Z}=$ nilai performansi

$x_{j}=$ level aktivitas $(\mathrm{j}=1,2,3, \ldots, \mathrm{n})$

$c_{j}=$ peningkatan nilai $\mathrm{z}$ yang dihasilkan dari peningkatan tiap level dari aktivitas $\mathrm{j}$ $b_{i}=$ jumlah sumber daya yang tersedia yang dialokasikan untuk setiap aktivitas

$a_{i j}=$ jumlah sumber daya ke-i yang dikonsumsi oleh setiap aktivitas $\mathrm{j}$.

Beberapa asumsi yang digunakan dalam program linier dengan metode simpleks yakni (Hillier \& Lieberman, 2015):

1. Proporsionalitas : kontribusi setiap aktivitas pada nilai fungsi tujuan atau fungsi objektif adalah proporsional pada setiap level aktivitas atau setiap level jumlah produk. Sebagai contoh proporsionalitas adalah $z=3 x_{1}+5 x_{2}$. Berdasarkan persamaan tersebut dapat disimpulkan bahwa jika jumlah produk 1 naik 1 satuan maka nilai $\mathrm{z}$ akan naik sebanyak 3 satuan dan jika jumlah produk 2 naik 1 satuan maka nilai $\mathrm{z}$ akan naik sebanyak 5 satuan. Contoh penyimpangan dari asumsi proporsionalitas adalah $z=3 x_{1}+5 x_{2}-1$. Berdasarkan hal tersebut kenaikan nilai $\mathrm{z}$ tidak sebanding dengan kenaikan jumlah aktivitas atau produk 1 dan produk 2 karena adanya pengurang yang nilainya sebesar 1. Hal ini terjadi karena kedua produk tersebut merupakan produk baru sehingga ada biaya start up. Contoh penyimpangan asumsi proporsionalitas adalah $z=3 x_{1}+5 x_{2}+1$. Hal ini terjadi karena adanya economic of scale di mana produksi produk dalam skala besar akan menghasilkan keuntungan yang lebih ekonomis.

2. Aditivitas : Setiap fungsi program linier (fungsi objektif dan fungsi konstrain) merupakan penjumlahan dari kontibusi individual dari setiap aktivitas. Sebagai contoh $z=3 x_{1}+5 x_{2}$. Nilai $\mathrm{z}$ merupakan hasil penjumlahan dari kontribusi produk 1 dan produk 2 . Penyimpangan aditivitas adalah $z=3 x_{1}+5 x_{2}+x_{1} x_{2}$. Nilai $\mathrm{z}$ bukan hanya hasil kontribusi dari produk 1 dan 2 saja melainkan hasil dari perkalian jumlah produk 1 dan produk 2. Hal ini dapat terjadi karena kedua produk tersebut menggunakan sarana promosi yang sama sehingga menimbulkan penghematan. Penyimpangan aditivitas yang lain adalah $z=3 x_{1}+5 x_{2}-x_{1} x_{2}$. Nilai $\mathrm{z}$ bukan hanya hasil kontribusi jumlah produk 1 dan 2 saja melainkan hasil dari pengurangan dari perkalian jumlah dua produk. Hal ini dapat terjadi di mana kedua produk menggunakan mesin produksi yang sama sehingga muncul biaya set up yang mengurangi laba dari kedua produk.

3. Divisibilitas : variabel dalam program linier meliputi bilangan integer dan non integer atau bilangan real. 
4. Kepastian : nilai setiap parameter dalam program linier bersifat konstan.

Selain itu terdapat juga asumsi tambahan yang berguna yakni linearity, simple objective, non-negativity, finiteness. Linearity menyatakan bahwa seluruh hubungan bersifat linier baik dalam fungsi tujuan maupun pada fungsi konstrain. Simple objective berarti bahwa fungsi tujuan dapat dimaksimalkan dan diminimalkan.

Non-negativity mengasumsikan bahwa setiap variabel keputusan yang memaksimumkan atau meminimumkan fungsi tujuan selalu bernilai nol atau positif dan tidak pernah bernilai negatif. Finiteness menyatakan bahwa konstrain dan variabel bersifat finite.

Program linier dengan metode simpleks banyak diaplikasikan dalam berbagai macam permasalahan. Program linier yang diimplementasikan pada permasalahan alokasi air pada beberapa tempat untuk memaksimalkan keuntungan ekonomi, keuntungan sosial dan keuntungan ekologi(Wang et al., 2015).

Program linier dengan metode simpleks juga diterapkan pada dunia bisnis untuk memaksimalkan keuntungan berdasarkan pada limitasi sumber daya (Karganov, 2013).

Metode simpleks diterapkan pada perusahaan pembuat pakan ternak dengan paradigma yang berbeda. Secara umum simpleks digunakan untuk memaksimumkan fungsi tujuan. Namun sebaliknya metode simpleks digunakan untuk meminimumkan fungsi tujuan. Secara umum hampir sama, fungsi konstrain dibuat berdasarkan pada data biaya bahan baku serta ketersediaan bahan baku atau modal. Bahan baku yang digunakan pada pembuatan pakan ternak antara lain yakni maize, soyabean, wheat bran, oyster shell, bone meal, salt, lysine, methionine, dan broiler premix. Terdapat 24 fungsi konstrain dan 1 fungsi tujuan yang diselesaikan secara simultan dengan simpleks. Terdapat beberapa asumsi yang digunakan yakni linearity, simple objective, certainty, additivity, divisibility, non-negativity, finiteness dan proportionality (Olugbenga et al., 2015).

Persaingan industri mendorong manajemen untuk mengoptimalkan variabel operasional seperti tingkat produksi. Kombinasi produk yang optimal merupakan permasalahan yang dihadapi oleh perusahaan. Penentuan kombinasi jumlah produk yang optimal dapat diselesaikan dengan program linier. Program linier dapat membantu perusahaan untuk menentukan jenis produk yang akan dibuat, jumlah yang akan dibuat, hal yang harus dilakukan jika terjadi kelebihan permintaan dan langkah untuk meningkatkan daya guna material (utilization). Model program linier yang diterapkan memiliki satu fungi tujuan dan beberapa fungsi konstrain (Vakilifard et al., 2013).

Perusahaan manufaktur pakaian juga mengimplementasikan program linier untuk menentukan kombinasi jumlah produk yang mampu memaksimumkan laba. Fungsi tujuan adalah kombinasi jumlah produk yang mampu memaksimumkan laba. Fungsi konstrain didefinisikan berdasarkan keterbatasan sumber daya seperti jumlah kain, benang, biaya tenaga kerja dan jam kerja yang meliputi aktivitas memotong, menjahit dan merapikan hasil jahitan. Model program linier tersebut diselesaikan dengan metode simpleks untuk mendapatkan kombinasi produk yang mampu memaksimalkan laba (Tesfaye et al., 2016).

Metode simpleks dapat juga diterapkan pada ICI yang memproduksi polyester, soda ash, paints and bahan-bahan kimia. Penyusunan fungsi konstrain dilakukan berdasarkan pada biaya sumber daya yang meliputi bahan baku, biaya penjualan, biaya distribusi, biaya administrasi, pajak dan diskon dari pemasok. Hasil perhitungan metode simpleks digunakan sebagai perencanaan produksi untuk memaksimumkan laba(Ullah Khan et al., 2011). 
Program linier juga dapat diterapkan pada perusahaan manufaktur sabun Informasi yang diperlukan untuk membuat fungsi konstrain antara lain adalah harga jual per kemasan dan biaya bahan baku yang digunakan per bulan serta bahan baku yang tersedia di perusahaan. Program linier dengan metode simpleks dilakukan untuk memaksimumkan laba dengan konstrain biaya dan ketersediaan bahan baku(Yahya et al., 2012).

Perusahaan manufaktur minyak nabati juga menerapkan program linier dengan metode simpleks untuk memaksimumkan keuntungannya. Perusahaan tersebut membuat dua produk utama yakni crude palm oil (CPO) dan palm kernel (PK). CPO biasanya digunakan untuk minyak goreng, margarin dan campuran mayonaise. PK biasanya digunakan untuk pembuatan sabun krim, sabun batangan dan sabun deterjen. Data yang digunakan adalah biaya bahan baku, ketersediaan bahan baku dan kapasitas produksi di setiap departemen. Fungsi konstrain tersebut digunakan sebagai pertimbangan untuk memaksimumkan laba (Murugan et al., 2013).

Permasalahan memaksimalkan laba namun dengan keterbatasan ketersediaan modal dan sumber daya juga dialami oleh pabrik kertas. Fungsi konstrain dibuat berdasarkan biaya bahan baku, ketersediaan modal, biaya pengoperasian boiler, biaya tenaga kerja dan biaya lainnya yang berhubungan dengan departemen produksi. Penyelesaian program linier dilakukan dengan bantuan grafik (Mokebe \& Joubert, 2013).

Program linier tidak hanya digunakan untuk memaksimalkan fungsi tujuan namun juga dapat digunakan untuk meminimalkan fungsi tujuan. Program linier digunakan untuk mengembangkan fleksibilitas proses produksi dan meminimalkan segala biaya yang berkaitan dengan produksi. Model program linier dapat diaplikasikan dengan sedikit modifikasi agar sesuai dengan permasalahan. Model ditekankan untuk minimisasi dengan proses penyelesaian yang hampir sama dengan maksimisasi namun terdapat sedikit modifikasi. Beberapa biaya yang harus ditekan adalah biaya procurement, biaya produksi, biaya persediaan dan biaya transportasi merupakan beberapa biaya yang harus diminimumkan (Veselovska, 2014).

Program linier merupakan teknik yang digunakan secara luas untuk membantu menemukan solusi dalam permasalahan manajerial yang kompleks. Terdapat banyak perusahaan yang melakukan trial and error dalam menentukan kapasitas produksinya sehingga perusahaan mengalami kesulitan dalam mengalokasikan sumber daya yang dimilikinya dan perusahaan mengalami kesulitan untuk memaksimalkan laba dan meminimalkan biaya. Perusahaan pembuat kue menerapkan program linier untuk menentukan kapasitas produksinya dengan tujuan untuk memaksimalkan laba dan meminimumkan biaya (Ailobhio et al., 2018).

Program linier sangat membantu perusahaan dalam menentukan kapasitas produksi dan pengalokasian sumber daya pada perusahaan roti yang memproduksi satu jenis roti namun dengan 3 macam ukuran ukuran sedang, ukuran besar dan ukuran ekstra besar. Masing-masing ukuran roti memberikan kontribusi laba. Perusahaan tersebut menerapkan program linier untuk menentukan ukuran roti yang mampu memberikan kontribusi laba yang maksimum. Hasil perhitungan program linier menunjukkan bahwa hanya roti dengan ukuran yang ekstra besar mampu memberikan kontribusi laba yang maksimum kepada perusahaan. Perusahaan roti tersebut menghentikan produksi roti dengan ukuran medium dan besar. Laba perusahaan meningkat dari $\$ 188.30$ menjadi \$198.48 (Abiodun \& Clement, 2017).

Seluruh permasalahan produksi diformulasikan dalam model matematis dan program linier digunakan untuk 
mengestimasi kapasitas produksi yang sesuai (Ezema \& Amakom, 2012).

Program linier juga dapat diterapkan di departemen personalia untuk menentukan komposisi karyawan yang mengikuti pelatihan. Karyawan dibagi menjadi 2 bagian yakni karyawan yunior dan senior. Fungsi tujuan adalah minimisasi biaya pelatihan untuk junior dan senior. Program linier dibagi menjadi beberapa model yang diaplikasikan pada beberapa departemen antara lain Non-academic model $=$ model I; School of Applied Science = model II; School of Management Studies $=$ model III; School of Engineering = model IV; School of Environmental Studies $=$ model V. Fungsi pembatas merupakan waktu yang tersedia untuk masing-masing staf atau karyawan (Olumuyiwa, 2016).

Perencanaan produksi agregat merupakan aktivitas yang sangat penting. Perusahaan yang sedang melakukan perencanaan agregat berusaha untuk mencapai beberapa tujuan utama yakni meminimumkan biaya produksi, memenuhi permintaan pelanggan, dan memaksimalkan kapasitas produksi. Tujuan tersebut harus diubah dalam bentuk matematis agar program linier dapat dijalankan. Tujuan tersebut menjadi biaya produksi sebesar $\mathrm{x}$ dolar, kecepatan produksi paling sedikit harus sesuai dengan permintaan, dan kecepatan produksi harus sesuai dengan kapasitas mesin atau stasiun kerja (Farzam Rad \& Shirouyehzad, 2014).

Penerapan program linier dengan metode simpleks tidak hanya dilakukan pada manufaktur saja melainkan juga dilakukan pada pertanian. Program linier dapat digunakan untuk memaksimalkan laba berdasarkan pada keterbatasan luas lahan, jam kerja buruh tani, modal dan tingkat konsumsi. Seluruh keterbatasan tersebut merupakan fungsi konstrain (Mugabe et al., 2014).

\section{METODE PENELITIAN} berikut:
1. Menentukan fungsi tujuan sebagaimana disajikan pada persamaan 1

2. Menentukan fungsi kendala atau kontrain sebagaimana disajikan pada persamaan 2.

3. Melakukan iterasi sebagai berikut :

a. Konversikan fungsi tujuan dan fungsi pembatas ke bentuk persamaan standar.

b. Untuk fungsi pembatas dengan tanda $(\leq)$, tambahkan variabel slack.

c. Untuk fungsi pembatas dengan tanda $(\geq)$, kurangi dulu dengan variabel surplus, kemudian tambahkan dengan variabel artificial.

d. Untuk fungsi pembatas dengan tanda (=), tambahkan variabel artificial.

e. Untuk fungsi tujuan tambahkan variabel slack (dengan koefisien 0), variabel surplus (dengan koefisien 0 ), dan variabel artificial (dengan koefisien $-\mathrm{M}$ ).

f. Selesaikan program linier melalui tabulasi dengan iterasi sebagai berikut :

1) Melakukan operasi baris elementer agar dapat diperoleh jawaban optimal.

2) Pada tahap awal, seluruh variabel yang ada di fungsi tujuan merupakan variabel non basic yang nilainya adalah nol.

3) Tentukan variabel basic masuk (berdasarkan koefisien $\mathrm{Zj}$ tersebesar)

4) Tentukan variabel non basic keluar (rasio yang terkecil antara ruas kanan dengan koefisien variabel basic masuk).

5) Tentukan kolom pivot (ubah nilai non basic variabel menjadi 1)

6) Lakukan operasi baris elementer berdasarkan pivot ini untuk baris lainnya termasuk baris $\mathrm{Zj}-\mathrm{Cj}$. Seluruh baris pivot yang lain selain variabel non basic nilainya adalah nol.

7) Proses iterasi dihentikan, apabila semua nilai pada $\mathrm{Zj}-\mathrm{Cj} \geq 0$ 


\section{HASIL DAN PEMBAHASAN}

Target dari UKM tersebut adalah memaksimalkan laba. Laba per kotak tempe adalah sebesar 55 ribu. Laba per kotak tahu adalah 80 ribu. Laba per kotak susu kedelai adalah 65 ribu rupiah. Fungsi tujuan adalah

$Z=50 x_{1}+80 x_{2}+65 x_{3}$

Fungsi pembatas yang pertama adalah jumlah bahan baku kedelai yang diperlukan. Satu kotak tempe membutuhkan kedelai sebanyak $15 \mathrm{Kg}, 1$ kotak tahu membutuhkan kedelai sebanyak $20 \mathrm{Kg}$ dan 1 kotak susu kedelai membutuhkan kedelai sebanyak $15 \mathrm{Kg}$. Total jumlah kedelai yang dapat disediakan oleh UKM tersebut per hari adalah $650 \mathrm{Kg}$ kedelai. Sehingga fungsi kendala pertama adalah :

$15 x_{1}+20 x_{2}+15 x_{3} \leq 650$

Fungsi pembatas yang kedua adalah jumlah bak perendaman dan perebusan. Bak perebusan dan bak perendaman merupakan alat yang sama. Masingmasing produk per kotak membutuhkan bak perendaman sebanyak 1 buah. Total jumlah bak perendaman yang dimiliki adalah 40 buah bak perendaman dengan kapasitas total $680 \mathrm{Kg}$. Sehingga fungsi konstrain atau kendala kedua adalah :

$15 x_{1}+20 x_{2}+15 x_{3} \leq 680$

Fungsi pembatas yang ketiga adalah kapasitas mesin giling. UKM tersebut memiliki 2 mesin giling dengan kapasitas masing-masing adalah $40 \mathrm{Kg}$ per jam. UKM tersebut beroperasi 12 jam per hari sehingga total kapasitas mesin giling adalah $960 \mathrm{Kg}$ per hari. Mesin giling hanya digunakan untuk produk tahu dan susu kedelai. Sehingga fungsi kendala yang ketiga adalah

$20 x_{2}+15 x_{3} \leq 960$

Fungsi pembatas yang keempat adalah proses perebusan. Seluruh produk menggunakan proses perebusan. UKM tersebut memiliki 2 kompor. Masingmasing kompor mampu merebus dengan kapasitas $100 \mathrm{Kg}$ per 3 jam. UKM beroperasi selama 12 jam per hari sehingga total kapasitas kompor adalah $800 \mathrm{Kg}$ per hari. Masing-masing produk memerlukan proses perebusan sehingga fungsi kendala yang keempat adalah

$$
15 x_{1}+20 x_{2}+15 x_{3} \leq 800
$$

Fungsi pembatas yang kelima adalah jumlah tenaga kerja. Untuk proses pembuatan tempe, diperlukan 1 orang tenaga kerja untuk membuat 10 kotak tempe per hari atau 0,1 orang per satu kotak tempe. Untuk proses pembuatan tahu diperlukan 2 orang tenaga kerja untuk membuat 10 kotak tahu per hari atau 0,2 orang per satu kotak tahu. Untuk proses pembuatan susu kedelai diperlukan 2 orang untuk membuat 8 kotak susu kedelai per hari atau 0,25 orang per satu kotak susu kedelai. UKM tersebut menyatakan bahwa utilitas tenaga kerja tidak boleh lebih dari 7 orang per hari. Fungsi kendala yang kelima adalah :

$0,1 x_{1}+0,2 x_{2}+0,25 x_{3} \leq 7$

Fungsi pembatas yang keenam adalah BEP. UKM tersebut mempersyaratkan bahwa total BEP adalah $200 \mathrm{Kg}$ sehingga fungsi kendala keenam adalah :

$15 x_{1}+20 x_{2}+15 x_{3}>200$

Fungsi pembatas yang ketujuh adalah kapasitas mesin peras. UKM tersebut memiliki 2 mesin peras dengan kapasitas masing-masing adalah $30 \mathrm{~kg}$ per jam. Total kapasitas mesin peras per hari adalah $720 \mathrm{Kg}$ per hari. Produk yang membutuhkan mesin peras adalah produk tahu dan susu kedelai. Sehingga fungsi kendala ketujuh adalah :

$20 x_{2}+15 x_{3} \leq 720$

Fungsi matematis awal diubah menjadi bentuk augmented sehingga persamaan matematisnya berubah menjadi berikut : Fungsi tujuan :

$\operatorname{Max} Z=55 x_{1}+80 x_{2}+65 x_{3}-M \overline{x_{10}}$

Fungsi pembatas jumlah bahan baku $15 x_{1}+20 x_{2}+15 x_{3}+x_{4}=650$ 
Fungsi pembatas jumlah bak perendaman

$15 x_{1}+20 x_{2}+15 x_{3}+x_{5}=680$

Fungsi pembatas kapasitas mesin giling

$20 x_{2}+15 x_{3}+x_{6}=960$

Fungsi pembatas proses perebusan

$15 x_{1}+20 x_{2}+15 x_{3}+x_{7}=800$

Fungsi pembatas jumlah tenaga kerja

$0,1 x_{1}+0,2 x_{2}+0,25 x_{3}+x_{8}=7$

Fungsi pembatas BEP

$15 x_{1}+20 x_{2}+15 x_{3}-x_{9}+\overline{x_{10}}=200$

Fungsi pembatas kapasitas mesin peras

$20 x_{2}+15 x_{3}+x_{11}=720$

Fungsi pembatas variabel $x_{1}, x_{2}, x_{3} \geq 0$.

Nilai variabel non basic adalah nol. Pada fungsi tujuan : Max $Z=55 x_{1}+80 x_{2}+65 x_{3}-M \overline{x_{10}}$, variabel artifisial merupakan variabel basic sehingga perlu dihilangkan koefisiennya pada fungsi tujuan. Oleh karena itu persamaan fungsi tujuan harus dieleminasikan dengan persamaan pembatas BEP. Fungsi tujuan harus diubah

Tabel 1. Iterasi Pertama

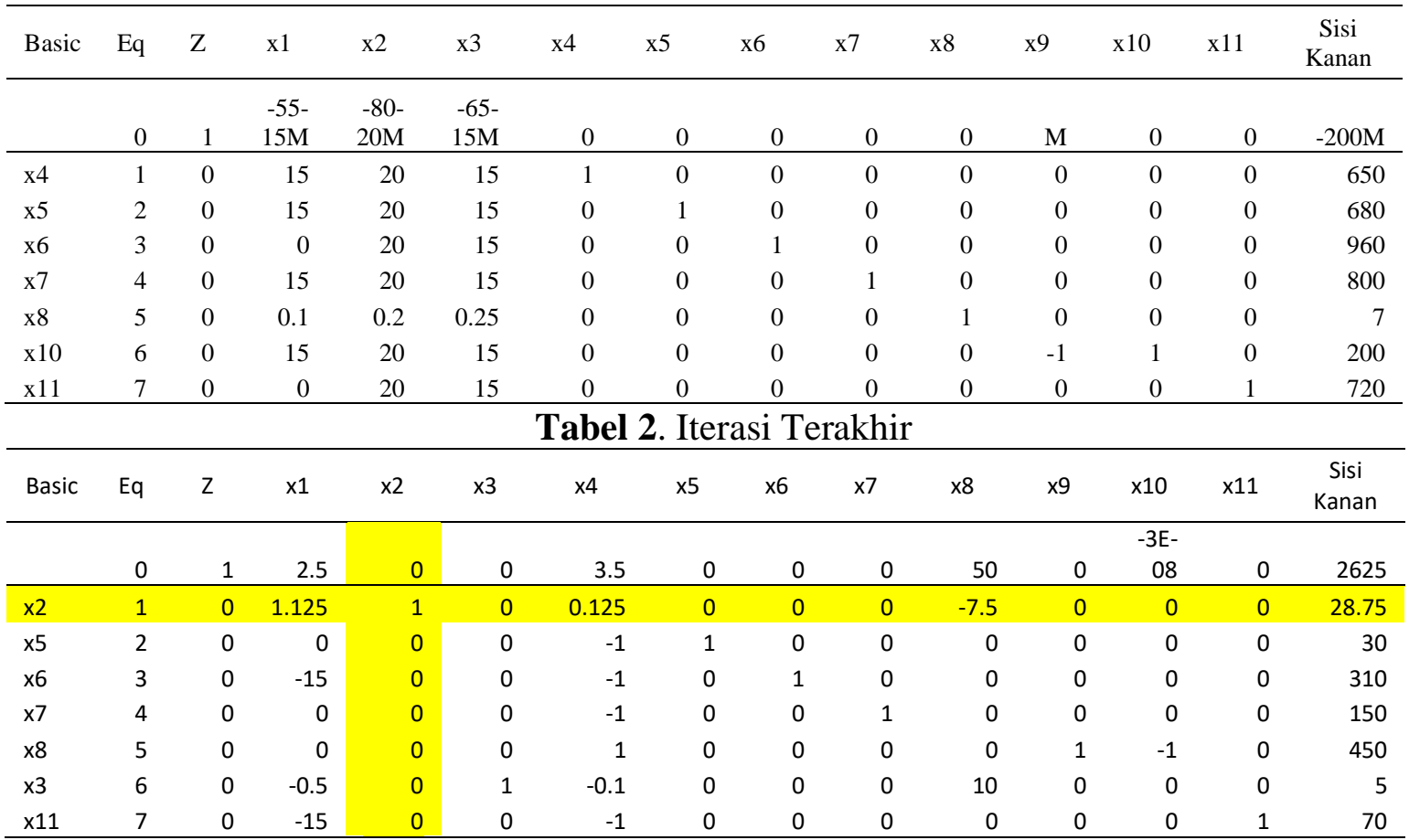

Selanjutnya adalah melakukan analisis sensitivitas. Persamaan program linier bentuknya

dari $Z=55 x_{1}+80 x_{2}+65 x_{3}-M \overline{x_{10}}$ menjadi $Z-55 x_{1}-80 x_{2}-65 x_{3}+M \overline{x_{10}}=0$.

Kemudian persamaan fungsi konstrain $15 x_{1}+20 x_{2}+15 x_{3}-x_{9}+\overline{x_{10}}=200$ dikalikan dengan $-\mathrm{M}$ dan didapatkan persamaan

$-15 M x_{1}-20 M x_{2}-15 M x_{3}+M x_{9}-M \overline{x_{10}}=-200 M$.

Selanjutnya persamaan

$Z-55 x_{1}-80 x_{2}-65 x_{3}+M \overline{x_{10}}=0$

dieleminasikan dengan persamaan $-15 M x_{1}-20 M x_{2}-15 M x_{3}+M x_{9}-M \overline{x_{10}}=-200 M$ dan didapatkan hasil sebagai berikut $Z-55 x_{1}-15 M x_{1}-80 x_{2}-20 M x_{2}-65 x_{3}$

$-15 M x_{3}+M x_{9}=-200 M$

dan kemudian disederhanakan menjadi persamaan berikut

$$
\begin{aligned}
& Z+(-55-15 M) x_{1}+(-80-20 M) x_{2} \\
& +(-65-15 M) x_{3}+M x_{9}=-200 M
\end{aligned}
$$

Selanjutnya dilakukan iterasi sebagai berikut. 
dinyatakan dalam bentuk matriks sebagai berikut :

$\left[\begin{array}{ccc}1 & -C & 0 \\ 0 & A & I\end{array}\right]\left[\begin{array}{c}Z \\ x \\ x_{s}\end{array}\right]=\left[\begin{array}{l}0 \\ b\end{array}\right]$

kemudian kedua sisi matriks dikalikan dengan matriks $\left[\begin{array}{cc}1 & C_{B} B^{-1} \\ 0 & B^{-1}\end{array}\right]$, dan hasil perkalian kedua sisi adalah :

$$
\left[\begin{array}{ccc}
1 & C_{b} B^{-1} A & C_{b} B^{-1} \\
0 & B^{-1} A & B^{-1}
\end{array}\right]=\left[\begin{array}{c}
C_{b} B^{-1} b \\
B^{-1} b
\end{array}\right]
$$

Analisis sensitivitas dilakukan pada jumlah kapasitas perebusan dan kapasitas penggilingan. Sebelum melakukan analisis sensitivitas perlu dilakukan identifikasi matriks sebagai berikut :

$$
\mathrm{B}^{-1}=\left[\begin{array}{ccccccc}
0.125 & 0 & 0 & 0 & -7.5 & 0 & 0 \\
-1 & 1 & 0 & 0 & 0 & 0 & 0 \\
-1 & 0 & 1 & 0 & 0 & 0 & 0 \\
-1 & 0 & 0 & 1 & 0 & 0 & 0 \\
1 & 0 & 0 & 0 & 0 & -1 & 0 \\
-0.1 & 0 & 0 & 0 & 10 & 0 & 0 \\
-1 & 0 & 0 & 0 & 0 & 0 & 1
\end{array}\right]
$$

Matriks $\mathrm{C}_{\mathrm{b}} \mathrm{B}^{-1}=$

$$
\left[\begin{array}{lllllll}
3.5 & 0 & 0 & 0 & 50 & -3 \mathrm{E}-08 & 0
\end{array}\right]
$$

Matriks $B^{-1} A=\left[\begin{array}{cccc}1.125 & 1 & 0 & 0 \\ 0 & 0 & 0 & 0 \\ -15 & 0 & 0 & 0 \\ 0 & 0 & 0 & 0 \\ 0 & 0 & 0 & 0 \\ -0.5 & -0.5 & 0 & 1 \\ -15 & 0 & 0 & 0\end{array}\right]$

Matriks $B^{-1} b=\left[\begin{array}{c}28.75 \\ 30 \\ 310 \\ 150 \\ 450 \\ 5 \\ 70\end{array}\right]$

Pada analisis sensitivitas, matriks $\mathrm{C}_{\mathrm{b}} \mathrm{B}^{-1}$ dan $\mathrm{B}^{-1}$ tidak berubah dan dapat langsung digunakan untuk melakukan perhitungan analisis sensitivitas. UKM tersebut ingin melihat sampai sejauh mana range nilai sumber daya. Berdasarkan matriks $\mathrm{B}^{-1}$, analisis sensitivitas hanya dapat dilakukan pada penyediaan kapasitas sumber daya manusia dan jumlah bahan baku. Hal ini dapat dilihat pada kolom pertama dan kolom kelima dari matriks $\mathrm{B}^{-1}$.

$$
\begin{aligned}
& \mathrm{B}^{-1} \mathrm{~b}=\left[\begin{array}{ccccccc}
0.125 & 0 & 0 & 0 & -7.5 & 0 & 0 \\
-1 & 1 & 0 & 0 & 0 & 0 & 0 \\
-1 & 0 & 1 & 0 & 0 & 0 & 0 \\
-1 & 0 & 0 & 1 & 0 & 0 & 0 \\
1 & 0 & 0 & 0 & 0 & -1 & 0 \\
-0.1 & 0 & 0 & 0 & 10 & 0 & 0 \\
-1 & 0 & 0 & 0 & 0 & 0 & 1
\end{array}\right]\left[\begin{array}{c}
650 \\
680 \\
960 \\
800 \\
7 \\
200 \\
720
\end{array}\right] . \\
& \mathrm{B}^{-1} \mathrm{~b}=\left[\begin{array}{c}
28.75 \\
30 \\
310 \\
150 \\
450 \\
5 \\
70
\end{array}\right]
\end{aligned}
$$

Berdasarkan matriks di atas, range kapasitas bahan baku dihitung dengan dua matriks yakni :

Matriks $B^{-1} \Delta b=$
$\left[\begin{array}{ccccccc}0.125 & 0 & 0 & 0 & -7.5 & 0 & 0 \\ -1 & 1 & 0 & 0 & 0 & 0 & 0 \\ -1 & 0 & 1 & 0 & 0 & 0 & 0 \\ -1 & 0 & 0 & 1 & 0 & 0 & 0 \\ 1 & 0 & 0 & 0 & 0 & -1 & 0 \\ -0.1 & 0 & 0 & 0 & 10 & 0 & 0 \\ -1 & 0 & 0 & 0 & 0 & 0 & 1\end{array}\right] \cdot\left[\begin{array}{c}\Delta b_{1} \\ 680 \\ 960 \\ 800 \\ 7 \\ 200 \\ 720\end{array}\right]$

$$
\text { dan Matriks } B^{-1} b=\left[\begin{array}{c}
28.75 \\
30 \\
310 \\
150 \\
450 \\
5 \\
70
\end{array}\right]
$$

Berdasarkan matriks tersebut dibuat beberapa pertidaksamaan sebagai berikut : 


$$
\begin{gathered}
28.75+0.125 \Delta b_{1}>0 \text { maka } \Delta b_{1}>-230 \\
-\Delta b_{1}+30>0 \text { maka } \Delta b_{1}<30 \\
-\Delta b_{1}+310>0 \text { maka } \Delta b_{1}<310 \\
-\Delta b_{1}+150>0 \text { maka } \Delta b_{1}<150 \\
\Delta b_{1}+450>0 \text { maka } \Delta b_{1}>-450 \\
-0,1 \Delta b_{1}+5>0 \text { maka } \Delta b_{1}<50 \\
-\Delta b_{1}+720>0 \text { maka } \Delta b_{1}<720
\end{gathered}
$$

Berdasarkan pertidaksamaan tersebut, range nilai perubahan $\mathrm{b}_{1}$ adalah $-230<\Delta b_{1}$ $<30$. Nilai $\mathrm{b}_{1}=650+\Delta b_{1}$ sehingga $\Delta b_{1}=\mathrm{b}_{1-}$ 650. Subtitusi nilai $\Delta b_{1}$ ke dalam pertidaksamaan $\quad-230<\Delta b_{1}<30$ menghasilkan $-230<b_{1}-650<30$, tambahkan tiap ruas dengan 650 sehingga menghasilkan $420<b_{1}<680$. Berdasarkan hasil perhitungan tersebut, rentang nilai $b_{1}$ adalah $420<b_{1}<680$. Pada rentang tersebut, nilai $b$ akan positif dan profit tetap positif. Rentang kapasitas sumber daya manusia dihitung dengan dua matriks yakni :

$$
\begin{aligned}
& \text { Matriks } B^{-1} \Delta b= \\
& {\left[\begin{array}{ccccccc}
0.125 & 0 & 0 & 0 & -7.5 & 0 & 0 \\
-1 & 1 & 0 & 0 & 0 & 0 & 0 \\
-1 & 0 & 1 & 0 & 0 & 0 & 0 \\
-1 & 0 & 0 & 1 & 0 & 0 & 0 \\
1 & 0 & 0 & 0 & 0 & -1 & 0 \\
-0.1 & 0 & 0 & 0 & 10 & 0 & 0 \\
-1 & 0 & 0 & 0 & 0 & 0 & 1
\end{array}\right] \cdot\left[\begin{array}{c}
\Delta b_{1} \\
680 \\
960 \\
800 \\
\Delta b_{2} \\
200 \\
720
\end{array}\right]}
\end{aligned}
$$$$
\text { dan Matriks B }{ }^{-1} b=\left[\begin{array}{c}
28.75 \\
30 \\
310 \\
150 \\
450 \\
5 \\
70
\end{array}\right]
$$

Berdasarkan matriks tersebut dibuat pertidaksamaan sebagai berikut :

$$
\begin{gathered}
-7.5 \Delta b_{2}+28.75>0 \text { maka } \Delta b_{2}<3.833 \\
10 \Delta b_{2}+450>0 \text { maka } \Delta b_{2}>-45
\end{gathered}
$$

Berdasarkan pertidaksamaan tersebut, rentang nilai $\Delta b_{2}$ adalah $-45<\Delta b_{2}<3.8333$.
Nilai $\quad \mathrm{b}_{2}=\Delta b_{2}+7 \quad$ sehingga $\quad \mathrm{b}_{2}-7=\Delta b_{2} \quad$. Subtitusi persamaan ini ke dalam $-45<\Delta b_{2}$ $<3.8333$ menjadi $-45<\mathrm{b}_{2}-7<3.8333$, kemudian tambahkan 7 ke seluruh sisi pertidaksamaan sehingga pertidaksamaan menjadi $-38<b_{2}<10.8333$. Karena nilai $b_{2}$ harus positif maka jumlah sumber daya manusia dapat dinaikkan menjadi 11 orang dengan profit yang tetap positif.

Seluruh variabel bernilai positif atau lebih besar dari nol. Fungsi tujuan sesuai dengan bentuk dasar program linier di mana berupa maksimisasi. Seluruh fungsi konstrain berbentuk pertidaksamaan lebih kecil kecuali pertidaksamaan fungsi pembatas BEP. Fungsi pertidaksamaan BEP harus diubah menjadi persamaan dengan menambahkan variabel artifisial dan variabel surplus. Variabel artifisial merupakan variabel dengan koefisien yang sangat besar dan metode simpleks berusaha menekan nilainya menjadi nol. Koefisien variabel artifisial pada persamaan nol atau persamaan tujuan bernilai negatif, hal ini terjadi karena fungsi tujuannya adalah maksimisasi sehingga variabel artifisial memiliki kecenderungan untuk menekan proses maksimisasi dengan menambahkan tanda negatif pada koefisiennya. Nilai variabel artifisial melalui simpleks akan dioptimasi menjadi nol. Jika nilai variabel artifisial sama dengan nol maka nilai profit akan menjadi maksimum. Hasil penelitian menunjukkan bahwa produk yang harus dibuat hanya produk tahu dan susu kedelai supaya laba UKM maksimum. Produk tempe tidak perlu dibuat. Hal ini dapat dianalisis dengan menggunakan fungsi tujuan dan fungsi pembatas. Fungsi pembatas sumber daya $0,1 x_{1}+0,2 x_{2}+0,25 x_{3} \leq 7$ menunjukkan bahwa untuk membuat produk tempe, tenaga kerja yang diperlukan lebih sedikit dari pada tenaga kerja untuk produk yang lain namun apabila ditinjau dari fungsi tujuan laba produk tempe lebih kecil dari pada produk yang lain. Hal ini terjadi karena biaya produksi tempe masih terlalu 
tinggi terutama biaya tenaga kerjanya karena produk tersebut tidak dapat langsung dijual dan harus difermentasi terlebih dahulu sehingga mengakibatkan utilisasi karyawannya rendah.

\section{KESIMPULAN}

Hasil penelitian menyatakan bahwa :

1. Komposisi produk yang harus dibuat adalah tahu sebanyak 28,75 atau 29 kotak dan susu kedelai sebanyak 5 kotak.

2. Hasil analisis sensitivitas menyatakan bahwa rentang nilai bahan baku adalah $420<b_{1}<680$ dan rentang jumlah tenaga kerja adalah $0<b_{2}<10.8333$. Jika nilai $b$ berada pada rentang tersebut maka profit akan tetap bernilai positif

\section{DAFTAR PUSTAKA}

Abiodun, R. O., \& Clement, A. O. (2017). Application of Linear Programming Technique on Bread Production Optimization in Rufus Giwa Polytechnic Bakery, Ondo State , Nigeria. American Journal of Operations Management and Information Systems, 2(1), 32-36. https://doi.org/10.11648/j.ajomis.201 70201.15

Ailobhio, T. D., Sulaiman, A. I., \& Akeyede, I. (2018). Optimizing Profit in Lace Baking Industry Lafia with Linear Programming Model. International Journal of Statistics and Applications 2018, 8(1), 18-22. https://doi.org/10.5923/j.statistics.201 80801.03

Balogun, O. S., Jolayemi, E. T., Akingbade, T. J., \& Muazu, H. G. (2012). Use Of Linear Programming For Optimal Production In A Production Line In Coca -Cola Bottling Company, Ilorin. International Journal of Engineering Research and Applications, 2(5), 2004-2007.

Ezema, B. I., \& Amakom, U. (2012). Optimizing Profit with the Linear
Programming Model: A Focus on Golden Plastic Industry Limited, Enugu, Nigeria. Interdisciplinary Journal of Research in Business, 2(2), 2046-714137.

Farzam Rad, M., \& Shirouyehzad, H. (2014). Proposing an Aggregate Production Planning Model by Goal Programming Approach, a Case Study. Data Envelopment Analysis and Decision Science, 2014, 1-13. https://doi.org/10.5899/2014/dea00061

Hillier, F. S., \& Lieberman, G. J. (2015). Introduction to Operation Research (V. Bradshaw (ed.); 10th ed.). Mc Graw Hill.

Karganov, S. A. (2013). Solving of linear programming by method of structural optimization. Scientific Journals Maritime University of Szczecin, 34(106), 48-58.

Mokebe, K. D., \& Joubert, D. J. W. (2013). Application of linear programming models to optimise pulp stock production process. Tappsa Journal, 1(1), 20-26.

Mugabe, D., Chipunza, N., Mupaso, N., Munyati, V. T., \& Makarudze, F. V. (2014). Estimation of Optimal Land Use Allocation Among Small Holder ( A1 ) Farmer Households in Zimbabwe . A Case Study of Long Croft Farm, in Mazowe District. Journal of Agricultural Science, 6(2), 170-181. https://doi.org/10.5539/jas.v6n2p170

Murugan, S., Choo, J. K., \& Sihombing, H. (2013). Linear Programming for Palm Oil Industry. International Journal of Humanities and Management Sciences, 1(3), 2-5.

Nadar, D. K. (2016). Some Applications of Simplex Method. International Journal of Engineering Research and Reviews, 4(1), 60-63.

Olugbenga, S., O, S. O., O, O. A., A, A. O., \& T, A. T. (2015). Journal of Nutrition \& Food Sciences Optimized Nutrients Diet Formulation of Broiler 
Poultry Rations in Nigeria Using

Linear Programming. Journal of Nutrition \& Food Sciences, 2-7. https://doi.org/10.4172/2155-

9600.S14-002

Olumuyiwa, O. (2016). Determination of the Optimal Cost of Training Staff in Tertiary Institution Using Linear Programming and Integer Linear Programming Model. The International Journal of Business \& Management, 4(11), 87-93.

Tesfaye, G., Berhane, T., Zenebe, B., \& Asmelash, S. (2016). A Linear Programming Method to Enhance Resource Utilization Case. International Journal for Quality Research, 10(2), 421-432. https://doi.org/DOI 10.18421/IJQR10.02-12 A

Ullah Khan, I., Bajuri, N. H., \& Jadoon, I. A. (2011). Optimal Production Planning for ICI Pakistan Using Linear Programming and Sensitivity Analysis. International Journal of Business and Social Science, 2(23), 206-212.

Vakilifard, H., Esmalifalak, H., \& Behzadpoor, M. (2013). Profit Optimization with Post Optimality Analysis Using Linear Programming. World Journal of Social Sciences, 3(2), 127-137.

Veselovska, L. (2014). A Linear Programming Model of Integrating Flexibility Measures into Production Processes with Cost Minimization. Journal of Small Business and Entrepreneurship Development, 2(1), 67-82.

Wang, Z., Yang, J., Deng, X., \& Lan, X. (2015). Optimal Water Resources Allocation under the Constraint of Land Use in the Heihe River Basin of China. Sustainability Journal, 7, 1558-1575.

https://doi.org/10.3390/su7021558

Yahya, W. B., Garba, M. K., \& Ige, S. O. (2012). Profit Maximization In A Product Mix Company Using Linear
Programming. European Journal of Business and Management, 4(17), 126-131. 